\title{
НИКОЛАЙ НИКОЛАЕВИЧ ДИКОВ - ОРГАНИЗАТОР АРХЕОЛОГИЧЕСКИХ ИССЛЕДОВАНИЙ НА СЕВЕРО-ВОСТОКЕ РОССИИ
}

\author{
Лебединцев А. И. \\ ФГБУН Северо-Восточный комплексный научно-исследовательский институт \\ им. Н. А. Шило ДВО РАН, г. Магадан \\ E-mail: lebedintsev@neisri.ru
}

\begin{abstract}
Представлены данные о научно-организационной деятельности заведующего лабораторией археологии, истории и этнографии СВКНИИ, доктора исторических наук, профессора, членакорреспондента РАН Н. Н. Дикова, о создании Северо-Восточно-Азиатской комплексной археологической экспедиции (СВАКАЭ) и результатах археологических исследований отрядами этой экспедиции. Отмечается важный вклад Н. Н. Дикова в организации археологических исследований на Северо-Востоке России, его достижения в изучении древних культур. Образование СВАКАЭ способствовало большему охвату археологическими исследованиями территории севера Дальнего Востока, открытию значительного количества археологических памятников на Чукотке, Камчатке, Колыме и Охотском побережье.
\end{abstract}

Ключевые слова: археологические исследования, Северо-Восточно-Азиатская комплексная археологическая экспедиция СВКНИИ, Н. Н. Диков, Северо-Восток России.

DOI: $10.34078 / 1814-0998-2021-2-105-115$

\section{Н. Н. ДИКОВ - ИССЛЕДОВАТЕЛЬ ДРЕВНИХ КУЛЬТУР СЕВЕРО-ВОСТОКА}

В феврале 2021 г. исполнилось 25 лет со дня смерти известного российского ученого, члена Президиума Дальневосточного отделения РАН, члена-корреспондента Российской академии наук, доктора исторических наук, профессора Николая Николаевича Дикова (1925-1996). Он координировал исследовательскую работу археологов Севера Дальнего Востока и осуществлял большую научно-организационную и научнообщественную деятельность. Являлся членом Национального комитета историков, членом Президиума ДВО РАН по гуманитарным наукам, членом Тихоокеанской научной ассоциации, членом Центрального совета Всероссийского общества охраны памятников истории и культуры, председателем Президиума Магаданского областного совета этого общества, членом комиссии при ЦК ВЛКСМ по премиям Ленинского комсомола, членом специализированного совета по защите диссертаций по специальностям археология и история при Институте археологии, истории и этнографии ДВО РАН.

(С Лебеденцев А. И., 2021
Н. Н. Диков участвовал в работе и выступал с докладами на VII, VIII, XI и XVII международных конгрессах исторических наук, на XIV Тихоокеанском научном конгрессе в 1979 г., на XI конгрессе ИНКВА в 1982 г., на историческом конгрессе 1985 г. в ФРГ, на научном симпозиуме 1985 г. в Индии и многих других. Награжден орденами «Знак Почета» (1975), Трудового Красного Знамени (1983), Отечественной войны II степени (1985).

Н. Н. Диков в 1949 г. окончил Ленинградский ордена Ленина государственный университет имени А. А. Жданова. Будучи студентом, в 1948-1949 гг. участвовал в Бурят-Монгольской археологической экспедиции Института истории материальной культуры АН СССР в Забайкалье под руководством А. П. Окладникова. В 1953 г. Н. Н. Диков защищает кандидатскую диссертацию «Бронзовый век Забайкалья», в которой археологические памятники Забайкалья эпохи бронзы впервые были представлены как единый свод с большим иллюстративным материалом. Несмотря на уговоры А. П. Окладникова остаться при ЛГУ, Н. Н. Диков в 1955 г. уезжает на Чукотку и работает директором Чукотского окружного краеведческого музея. Уже в 1956-1959 гг. он проводит сплошную разведку внутриконти- 


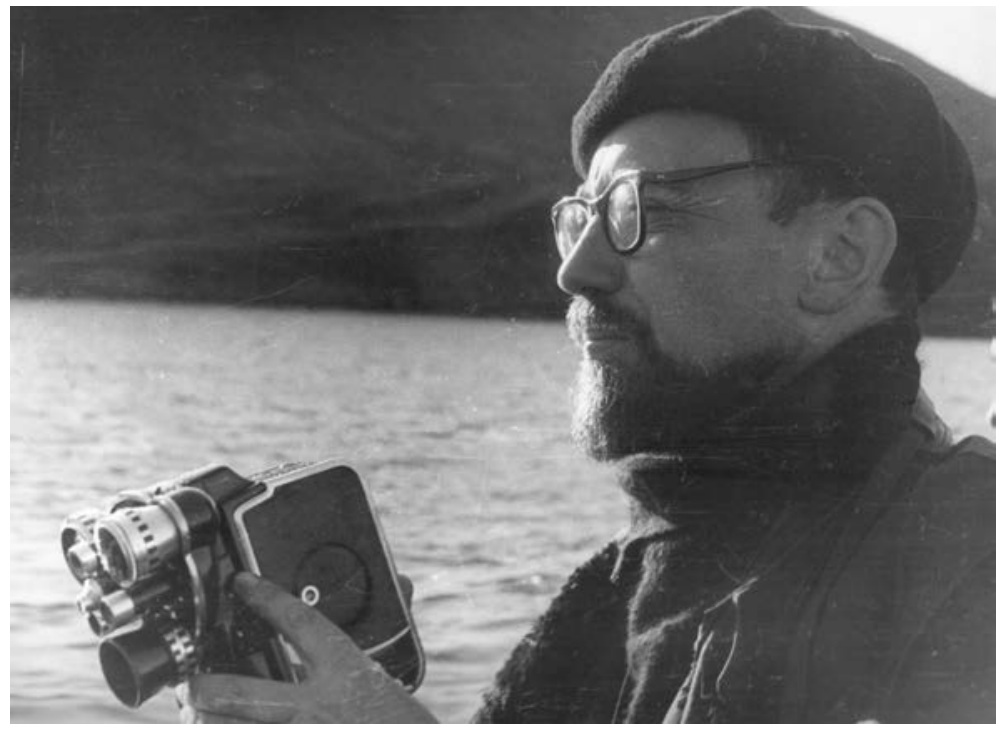

Фото 1. Николай Николаевич Диков, 1970-е гг.

Photo 1. Nikolay N. Dikov, 1970s

нентальных районов и морского побережья Чукотки, где обнаружил множество неолитических стоянок, древнеэскимосских поселений и могильников. Благодаря инициативе и стараниям Н. Н. Дикова, в 1958 г. было начато издание «Записок Чукотского краеведческого музея».

После организации в 1960 г. в Магадане Северо-Восточного комплексного научноисследовательского института Николаю Николаевичу Дикову было предложено возглавить гуманитарную лабораторию, которой он и руководил 35 лет. С этого времени начинаются широкомасштабные археологические исследования на территории Магаданской и Камчатской областей (фото 1).

В 1961 г. Н. Н. Диков организует свою первую экспедицию на Камчатку. Основной маршрут проходил по р. Камчатка. В результате этой экспедиции выявлено около полусотни древнеительменских стоянок и поселений. На берегу Ушковского озера в 1964 г. были найдены свидетельства пребывания человека в позднем палеолите. На стоянках Ушки I, V и VI впоследствии удалось выявить две верхнепалеолитические культуры. Это открытие впервые позволило подойти к проблеме древнего заселения СевероВосточной Азии и Америки. Открытие ушковских стоянок является выдающимся в археологии Севера Дальнего Востока.

В 1962 г. в низовьях р. Пенжина Н. Н. Диков обнаруживает поселения морских зверобоев (Зеленый мыс, Большой мыс). В 1963 г. морское побережье на северо-восточной Чукотке подверглось сплошному археологическому обследованию. Этот маршрут был пройден на вельботах. В результате были выявлены и исследованы древнеэскимосские поселения и могильники в Яндогае, Нунямо, Чини, Энмынытныне, Инчоуне, Утене, Чегитуне, Экичувервееме, Энурмино, на о. Илитлен, в Нешкане, Дженретлене, на косе Беляка, в Анаяне, на о. Колючин, в Ванкареме. В этот полевой сезон в 1963 г. были продолжены работы на Уэленском могильнике. В 1964 г. проведено обследование о. Беринга (Командорские острова), где были выявлены поселения поздних приморских охотников.

В 1965 г. Н. Н. Диковым полностью был раскопан Чинийский могильник, расположенный на пологом северном склоне возвышенности м. Чини между поселками Нунямо и Наукан. Получен большой и разнообразный погребальный материал, оставленный древними морскими зверобоями. Были продолжены раскопки Энмынытнынских могильников, где собран большой археологический материал, в том числе много высокохудожественных косторезных предметов.

В 1966 г. Н. Н. Диков исследует нижнюю УстьБельскую стоянку, ставшую основным памятником выделенной анадырско-майнской (вакаревской) культуры (середина II тыс. н. э.).

В 1967 и 1968 г. Н. Н. Диков исследует уникальный археологический памятник Чукотки пегтымельские петроглифы. Было выявлено более 100 композиций наскальных рисунков, рассказывающих об охоте на оленей, китов, косаток, лахтаков и нерп. Иногда встречаются там изображения белого медведя, песцов, волков, водоплавающих птиц. Особую группу составляют разнообразные антропоморфные фигуры, в которых угадываются мухоморы. Аналогии грибовидным рисункам Н. Н. Диков прослеживает в культовом искусстве мелкой пластики древних майя в Америке, в петроглифах Южной Сибири и юга Дальнего Востока. Им была прослежена эволюция канонических образов и композиций. Петроглифы создавались, как он предполагал, в течение длительного времени (I тыс. до н. э. - I тыс. н. э.). Большинство сюжетов петроглифов Н. Н. Диков считал чукотскими и эскимосскими (Диков, 1971).

О работе в эти годы, а также об основных интересных памятниках повествуется в научнопопулярной книге «Древние костры Камчатки и Чукотки: 15 тысяч лет истории» (Диков, 1969). Н. Н. Диковым на побережье Чукотки были найдены более 40 новых археологических памятников, в том числе 14 древних могильников. Три могильника (два Энмынытнынских и Чиний- 
ский) были раскопаны полностью, а остальные частично. Новые палеоантропологические и археологические материалы получены из могильников. Прослежено распространение древнеберингоморской и бирниркской культур к западу от Берингова пролива. Им были выделены два основных направления распространения элементов эскимосских культур. Одно, более древнее (II-I тыс. до н. э.), шло с юга, со стороны Камчатки и Алеутских островов; другое, более позднее, - с берегов Берингова пролива (в середине I тыс. до н. э.), а затем с Аляски и из Канады на запад (со II тыс. н. э.).

С начала 1960-х гг. Н. Н. Диков активно обследует Камчатку. Он проводит разведки и раскопки возле Петропавловска-

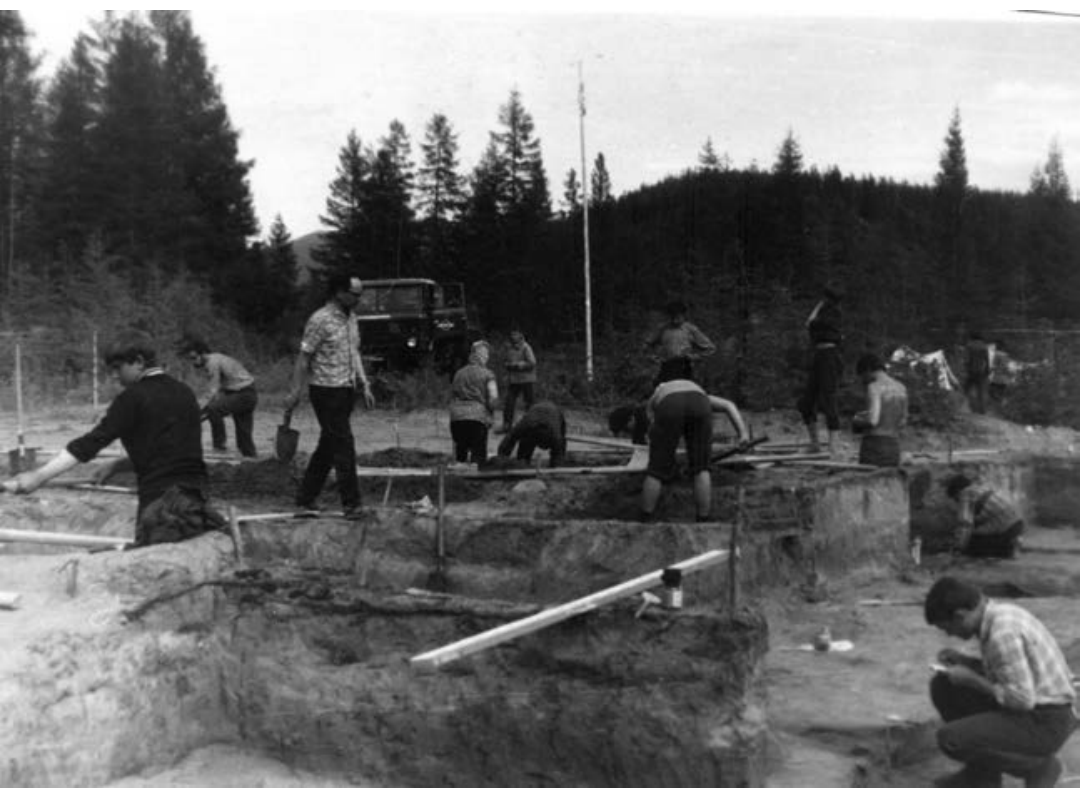

Фото 2. Раскопки стоянки Сибердик. Н. Н. Диков среди студентов и школьников, 1974 г.

Photo 2. Excavations at the Siberdik Site. N. N. Dikov among Pedagogic Institute and high school students, 1974 обнаружена Авачинская неолитическая стоянка, на которой потом были выявлены интереснейшие материалы тарьинской поздненеолитической культуры.

В 1972 г. Н. Н. Диков защитил докторскую диссертацию «Древние культуры Камчатки и Чукотки», в которой обобщил результаты своих многолетних исследований. На основе полученных археологических материалов, используя естественно-научные методы, Н. Н. Диков предложил периодизацию древних культур Крайнего Северо-Востока, а также рассмотрел проблему этнической дифференциации аборигенного населения края в ходе его исторического развития.

Н. Н. Диков проводит интенсивные разведки и раскопки в зоне затопления Колымской ГЭС (1971-1975 гг.), завершившиеся открытием ряда местонахождений позднеплейстоценового и раннеголоценового возраста. Были исследованы Сибердиковская многослойная стоянка при впадении р. Детрин в Колыму (фото 2), стоянка Конго в устье впадающего в Колыму одноименного ручья и многослойная стоянка на р. Малтан. Продолжаются ежегодные раскопки Ушковской палеолитической стоянки на Камчатке (Диков, 1976).

В 1974 г. вышла в свет фундаментальная коллективная монография по истории Чукотки (Очерки..., 1974). В ней были обобщены результаты планомерных археологических исследований. В результате многолетних систематических разведок и раскопок были выявлены общие контуры древней истории этого региона с древнейших времен. Позднее, в 1989 г., переработанная и дополненная новыми материалами, эта книга выходит под названием «История Чукотки с древнейших времен до наших дней».

Итогом 20-летних исследований Н. Н. Дикова на Северо-Востоке стала двухтомная монография «Археологические памятники Камчатки, Чукотки и Верхней Колымы» и «Древние культуры Северо-Восточной Азии» (Диков, 1977, 1979). Первая книга является источниковедческой, где приведены топография, стратиграфия, характеристика комплексов, классификация и датировка археологических памятников, обнаруженных Н. Н. Диковым в 1956-1975 гг. Во второй книге автор характеризует древние культуры СевероВостока Азии в их развитии. В 1979 г. за научные достижения Н. Н. Диков был избран членомкорреспондентом Академии наук СССР.

\section{СОЗДАНИЕ СВАКАЭ}

Для активизации археологических исследований и расширенного обследования территорий в ряде регионов Восточной Сибири создавались постоянно действующие археологические экспедиции. В 1953 г. была образована Дальневосточная археологическая экспедиция, отряды которой работали в Приморье, Хабаровском крае и на Сахалине. В Якутии Институт языка, литературы и истории Якутского филиала СО АН СССР в 1965 г. организовал Приленскую археологическую экспедицию. Необходимость создания такого объединения для широкого археологического изучения огромных пространств Севера Дальнего Востока возникла и в СВКНИИ ДВНЦ АН СССР. 
Организованная в 1975 г. и руководимая Н. Н. Диковым Северо-Восточно-Азиатская комплексная археологическая экспедиция (СВАКАЭ) вела эффективные поиски и исследования археологических памятников Камчатки, Чукотки, Колымы и Охотского побережья (начальники отрядов сотрудники СВКНИИ и аспиранты Т. М. Дикова, М. А. Кирьяк, А. И. Лебединцев, А. К. Пономаренко, Т. С. Теин, А. А. Орехов, В. И. Рубан). Определенные надежды Н. Н. Диков возлагал на С. П. Ефимова как археолога, который активно участвовал во многих археологических экспедициях СВКНИИ. К СВАКАЭ были подключены сотрудники других организаций, занимающие выявлением и изучением древних памятников на Севере Дальнего Востока (В. Н. Малюкович, А. В. Пташинский, А. В. Гоков, С. Б. Слободин). В работах СВАКАЭ принимали участие историки лаборатории археологии истории и этнографии СВКНИИ (И. Д. Бацаев, В. М. Хлыпалов, В. И. Ушкалов). Побережья Северо-Западного Берингоморья вместе с А. А. Ореховым обследовал этнограф В. В. Леонтьев. Т. М. Дикова принимала участие в раскопках Ушковской стоянки на Камчатке в 1976 и 1980 г. В экспедиции на Ушках участвовали сахалинские археологи В. О. Шубин и О. А. Шубина. Подготовкой и организа-

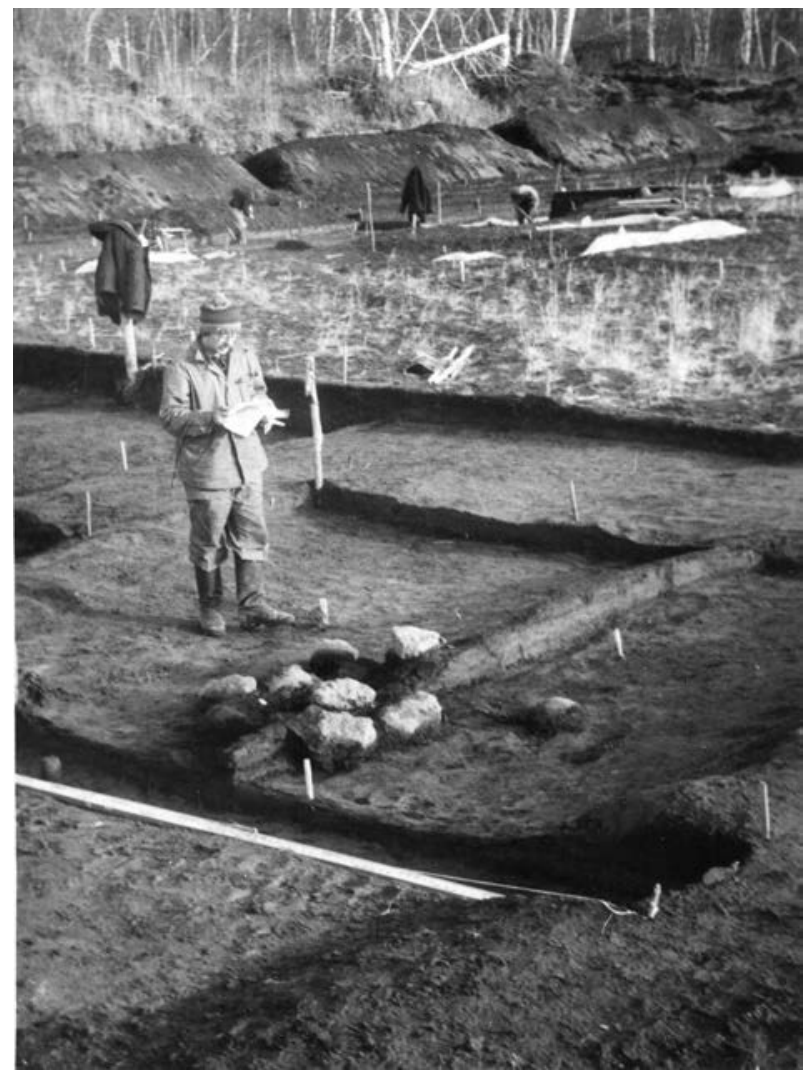

Фото 3. Ушковская стоянка на Камчатке. Зарисовка плана раскопа А. И. Лебединцевым, 1980-е гг.

Photo 3. Ushki site in Kamchatka. Sketch of the excavation plan by A. I. Lebedintsev, 1980s цией работ на стоянке Ушки I, фиксацией археологических находок, зарисовкой стенок раскопов и планов занимался в 1980-х гг. А. И. Лебединцев в качестве заместителя начальника экспедиции и начальника отряда (фото 3). Графические иллюстрации многих публикаций по археологии сотрудников лаборатории были выполнены лаборантом, художницей Л. Н. Коршковой.

Существенное содействие СВАКАЭ оказывали геологи, геофизики, палинологи, геоморфологи СВКНИИ и других организаций. В проводимых исследованиях на Чукотке и в Приохотье принимали участие геологи Ю. А. Колясников, Г. И. Казинская, Н. Е. Савва и ботаник А. Е. Катенин (Новейшие..., 1980). Геолого-археологическим отрядом (Ю. А. Колясников) были обнаружены первые следы палеолита на юге Чукотки (Новые..., 1979). Геоморфологические исследования в районе ушковских стоянок на Камчатке проводили Э. Э. Титов (1980) и В. Ф. Иванов (1990). Палеомагнитные работы на ушковских многослойных стоянках проведены Ю. Г. Добрецовой, В. И. Алексеевым и Ю. В. Малеванным. Радиоуглеродным датированием, палинологическим изучением древних стоянок СевероВостока занимался А. В. Ложкин. Многие годы в раскопках участвовали студенты Магаданского государственного педагогического института (в основном историки).

Начальником СВАКАЭ был назначен заведующий лабораторией археологии, истории и этнографии СВКНИИ д. и. н. Н. Н. Диков. В 1975 г. полевые отряды работали в 11 различных районах Северо-Востока (от о. Врангеля до м. Лопатка на юге Камчатки и от верховьев Колымы до Берингова пролива).

Полевыми отрядами СВАКАЭ открыты сотни древних стоянок. Исследователями накоплен материал по проблемам древней истории происхождения народов Северо-Востока, развития их культуры и формирования образа жизни. Основными задачами исследований были проблемы первоначального заселения региона и происхождения коренных народов. В результате появились новые материалы, впоследствии изложенные в монографиях. Материалы СВАКАЭ публиковались в сборниках научных трудов СВКНИИ (Новые..., 1979; Новейшие..., 1980; Новое..., 1985; Древние..., 1990; Археологические..., 1996), в ежегодно издаваемых издательством «Наука» «Археологических открытиях», в различных научных журналах и других периодических изданиях.

На протяжении ряда лет (1972, 1973, 1975, 1977, 1979 г.) в самых труднодоступных районах южной Камчатки - м. Лопатка, Налычево, Явино, Курильское озеро и о. Шумшу работала Т. М. Дикова (1933-1981). Она являлась руко- 
водителем Южно-Камчатского археологического отряда СВКНИИ (фото 4). На южной Камчатке ею были открыты несколько десятков археологических памятников. Она изучала древнеительменскую культуру, выявляла южные границы, связи с соседними культурами и их роль в истории Дальнего Востока. Археологические исследования Т. М. Диковой на южной Камчатке внесли значительный вклад в изучение древнейшей истории ительменов. Ею были получены достаточно представительные и интересные материалы со стоянок и поселений древних охотников и рыболовов Камчатки. Т. М. Дикова предложила периодизацию для древних стоянок южной Камчатки (выделены ранний, средний и поздний периоды), дала характеристику каждому из этих этапов. Ею установлено, что айны не обитали постоянно на юге Камчатки, но оказывали определенное влияние на культуру ительменов этой части Камчатки. Исследования Т. М. Диковой были обобщены и представлены в большой монографии о древних культурах южной Камчатки, вышедшей уже после ее смерти (Дикова, 1983).

С 1975 г. на Восточной Камчатке успешно работал Восточно-Камчатский отряд (руководитель А. К. Пономаренко) (фото 5). Проведены разведочные работы, а также раскопки трехслойной Жупановской стоянки. Были получены важные материалы по тарьинской культуре, новые и обильные данные по кроноцкому этапу древнеительменской культуры. В верхнем слое этой стоянки исследованы древнеительменские жилища, где в одном из них оказались предметы, характерные для айнской культуры Курильских островов (бронзовые японские монеты и курительные трубки, фрагменты фарфоровой посуды, стеклянные бусы, железные ножи). Раскопки стоянки Жупаново проводились в 1975, 1976, 1978-1980 гг., а затем были продолжены в 19921994 гг. Им выполнены разведочные работы во многих районах Камчатки. Материалы опубликованы в монографии «Древняя культура ительменов Восточной Камчатки» (Пономаренко, 1985) и других различных

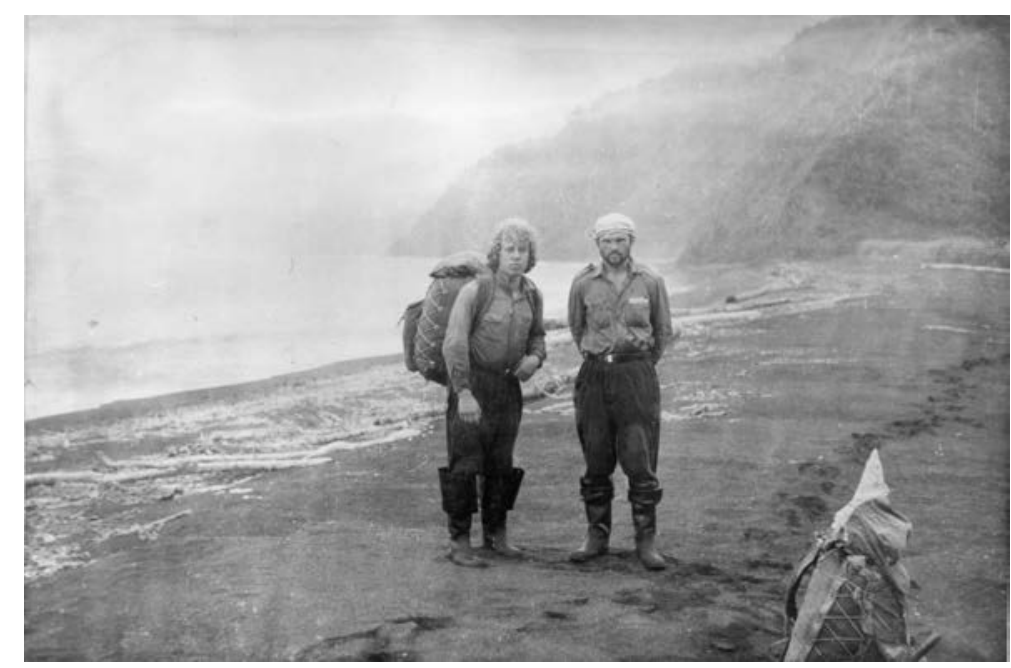

Фото 5. Маршрутные работы Восточно-Камчатского отряда. Справа - А. К. Пономаренко

Photo 5. Route works of the East Kamchatka detachment. On the right, A. K. Ponomarenko публикациях. В них рассматриваются особенности древних культур Камчатки, прослеживается эволюционный путь развития основных видов хозяйства, особенности духовной культуры, общие контуры этнокультурных связей населения Камчатки с народами сопредельных территорий в древности.

Западно-Камчатский отряд (руководитель В. И. Рубан) осуществлял археологические разведки на западном побережье Камчатки. В 1975 г. в районе к северу от пос. Ича до устья р. Тигиль В. И. Рубаном были открыты 22 стоянки 


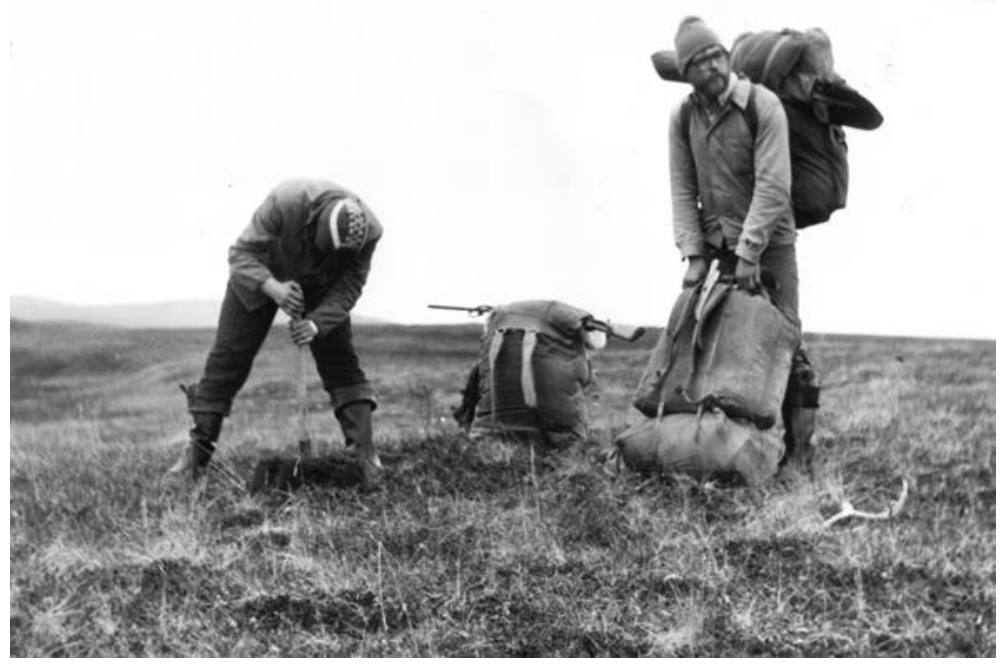

Фото 6. Археологические разведки на западном побережье Камчатки, 1985 г. Справа - А. В. Пташинский

Photo 6. Archaeological prospecting on the western coast of Kamchatka, 1985. On the right, A. V. Ptashinsky

и осмотрены раскопы В. И. Иохельсона 1911 г. (стоянки Ковран и Кульки) (Рубан, 1979). В. И. Рубан выявил Ичинскую, Ковранскую, Тигильскую и Паланскую группы стоянок. В результате этих работ был выделен ряд разновременных культур (раннего неолита, позднего неолита, древнеительменской и древнекорякской культур). Им проведена корреляция археологических стоянок западного побережья Камчатского полуострова и долины р. Камчатка. Впоследствии обследованием западного побережья занимался А. К. Пономаренко (фото 6).

Исследованием неолитической стоянки Халактырка, расположенной в 20 км на северо-восток от Петропавловска-Камчатского, в 1978 г. занимались сотрудники Камчатского областного краеведческого музея (В. Н. Малюкович - руководитель отряда и Е. М. Евстратенко).

С 1987 г. Северо-Камчатский отряд СВАКАЭ (руководитель А. В. Пташинский) провел сплошную археологическую разведку побережий Пенжинской губы (Пташинский, 1989). За два полевых сезона было обследовано западное и северное побережье от границы Камчатской области до с. Манилы, где были обнаружены 24 новые стоянки и осмотрены 17 корякских поселений. Группа древнекорякских стоянок исследована А. В. Пташинским (1990) на п-ове Елистратова. Им были выявлены новые типы ритуальных памятников, связанные с культом морских живот- ных. На северо-западном побережье им выделены памятники типа Теви (I тыс. н. э.), имеющие аналоги в древнеительменской и в древнекорякской культурах, ряд элементов характерен для древнеэскимосской, алеутской и охотской культур (Пташинский, 2002).

Нижнекамчатским отрядом CВАКАЭ (руководитель А. В. Гоков) были предприняты охранные раскопки русского поселения Нижнекамчатск на р. Радуга (Гоков, 1989, 1990). В ходе раскопок удалось выявить остатки жилищно-хозяйственных комплексов, предметы быта русских первопоселенцев. Среди находок ножи, топоры, наконечники стрел, ножницы, шилья, иглы, детали ударнокремневых ружейных замков, фрагменты медной, глиняной, фарфоровой, фаянсовой и стеклянной посуды, фрагменты слюдяных оконниц, остатки рыболовных снастей, детали одежды, а также монеты, украшения, свинцовые пломбы-печати. Материалы из культурного слоя этого поселения являются важным источником для изучения материальной культуры русского населения Камчатки.

Т. С. Теин (1938-2005) возглавлял Северочукотский отряд СВАКАЭ. К концу 1980-х гг. он провел семь очень успешных полевых сезона и в труднейших условиях Северной Чукотки собрал значительный археологический материал.

Т. С. Теин провел раскопки на о. Врангеля, где исследовал в 1976, 1977 и 1981 г. палеоэскимосскую стоянку Чертов Овраг (Теин, 1983) (фото 7).

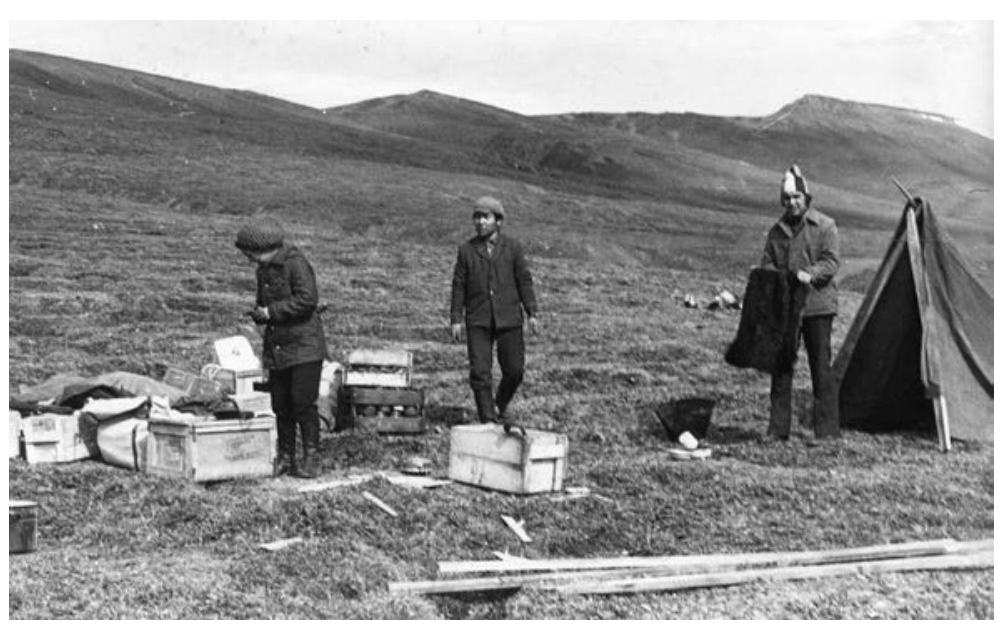

Фото 7. Высадка полевого отряда на о. Врангеля, 1976 г. В центре - Т. С. Теин

Photo 7. Field detachment landing on Wrangel Island, 1976. In the center, T. S. Tein 
В 1979 г. он на о. Ратманова исследовал стоянку оквикского и древнеберингоморского времени. На м. Рыркайпий (1976 г.) и м. Якан (1985 г.) он изучал пунукские стоянки, на м. Биллингса (1986 г.) - жилище древнеберингоморского времени (Теин, 1991).

Обширные полевые исследования археологии Западной Чукотки с конца 1970-х гг. проводила М. А. Кирьяк (1937-2017) (Западно-Чукотский отряд). В монографии «Археология Западной Чукотки в связи с юкагирской проблемой» она представила периодизацию древних культур этого региона от верхнего палеолита до периода палеометалла (Кирьяк, 1993). Поздненеолитические материалы Западной Чукотки она использовала для этногенетических построений. Эта работа внесла коррективы в существующие представления о формировании и развитии древних культур Северо-Восточной Азии и затронула остродискуссионные проблемы, в том числе проблему происхождения юкагиров.

Западно-Берингоморский отряд под руководством аспиранта А. А. Орехова исследовал в 19751976 и 1977 г. археологические памятники на побережье от м. Гека на севере до м. Олюторский на юге, которые были отнесены к лахтинской (древнекерекской) культуре. Им даны этапы развития этой культуры, социально-экономическая и историкокультурная реконструкция (Орехов, 1987).

Во второй половине 1970-х гг. Колымский отряд под руководством Н. Н. Дикова проводил на Верхней Колыме раскопки стоянок Конго и Малтан (Диков, 1976). С 1978 г. планомерные археологические работы в Нижнем Приколымье осуществлял отряд СВАКАЭ, руководителем которого была М. А. Кирьяк. Были предприняты разведки и раскопки в бассейнах рр. Малый Анюй, Омолон, Олой, Колыма. Большинство исследованных археологических памятников относится к позднему неолиту. Важным открытием явилось обнаружение верхнепалеолитических памятников Большой Эльгахчан I и Тытыльваам IV. Верхне-Колымским археологическим отрядом (руководитель С. Б. Слободин) проводились исследования стоянок каменного века в различных районах Верхней Колымы и Континентального Приохотья (Слободин, 1995).

А. И. Лебединцевым, руководителем Североохотского отряда, в 1979 г. было начато обследование СевероЗападного Приохотья. В результате на этом участке побережья выявлены новые стоянки эпохи неолита, палеометалла, а также стоянки древнекорякской культуры. В монографии

А. И. Лебединцева (1990) рассмотрены проблемы заселения Охотского побережья, происхождения древнекорякской культуры, «пеших тунгусов», возникновения морского зверобойного промысла в Северном Приохотье. Исследуются вопросы культурных связей в этом регионе. Большое внимание уделяется исследованию впервые выделенной автором токаревской культуры, которая являлась основой формирования древнекорякской культуры. Для токаревской культуры были определены характерные признаки, сделан вывод о важной роли Нижнего Амура в формировании культур в Северо-Западном Приохотье.

Чтобы увеличить время полевых работ, Н. Н. Диков в летнее время осуществлял маршруты по Восточной Чукотке (Чукотский отряд), а осенью проводил раскопки на Камчатке (Ушковский отряд), где было гораздо теплее по сравнению с Чукоткой

В 1975 г. на о. Врангеля Н. Н. Диков обнаруживает древнейшую в Азии палеоэскимосскую культуру. Материалы стоянки Чертов Овраг, где было обнаружено большое количество каменных орудий и поворотный наконечник гарпуна, имеют много общего с комплексами древнейших палеоэскимосских памятников арктической Америки. Датировалась стоянка концом II - началом I тыс. до н. э. (Диков, 1979).

В 1980-е гг. Н. Н. Диков с большой тщательностью обследует Чукотский полуостров, осуществляя продолжительные маршруты на вездеходе вдоль побережья Берингова моря от Провидения до Лаврентия и углубляясь во внутренние районы Чукотки (фото 8).

Важным следствием этих экспедиций является открытие палеолитических и мезолитических стоянок. Основные результаты архео-

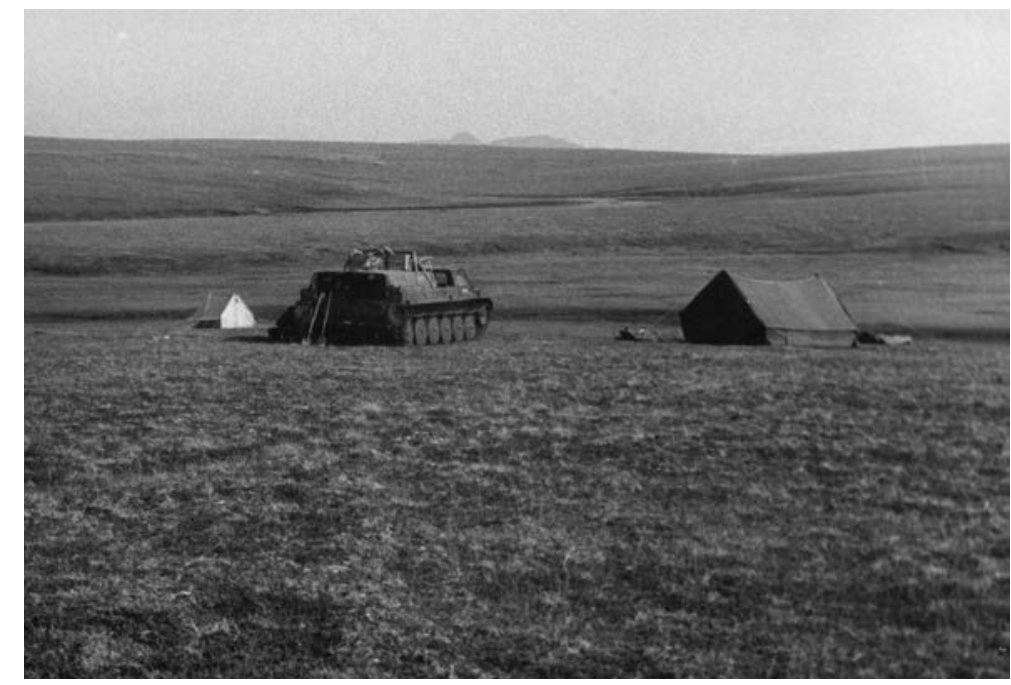

Фото 8. Полевые работы Чукотского отряда, 1980-е гг. Photo 8. Field works of the Chukotka detachment, 1980s 


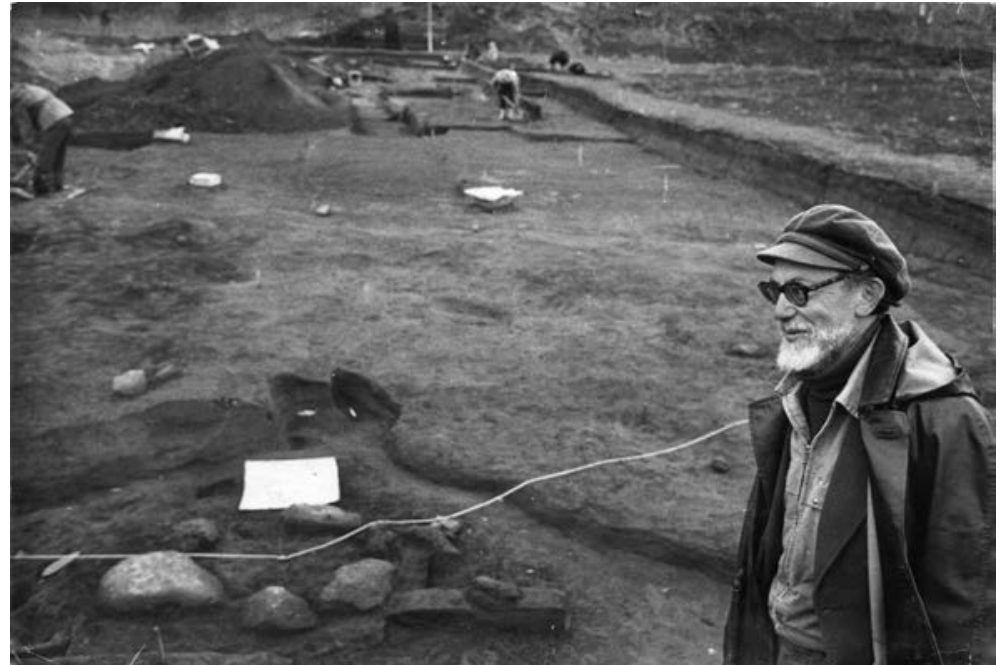

Фото 9. Н. Н. Диков на Ушковской палеолитической стоянке Photo 9. N. N. Dikov at the Ushki Paleolitic site боратории В. М. Хлыпалов и И. Д. Бацаев). В конце 1980-х гг. там установили балок из бруса. В 1994 г. Н. Н. Диков занимался подготовкой материалов к монографии по Ушковским палеолитическим памятникам. К сожалению, полностью опубликовать материалы многолетних исследований Ушковских стоянок ему не удалось.

Н. Н. Диков стремился увеличить количество археологов в лаборатории археологии, истории и этнографии СВКНИИ. Так, например, в рапорте на имя первого заместителя директора СВКНИИ к. г.-м. н. В. И. Гончарова он писал: «В связи с необходимостью развития археологических исследований на Севере Дальнего Востока и особой ответственностью, возложенной на меня в этом деле Отделением истории Академии наук СССР,

логических разведок на востоке Чукотского полуострова в 1979-1986 гг. были опубликованы в монографии (Диков, 1993б). Более 30 лет Н. Н. Диков проводил раскопки Ушковской палеолитической стоянки (фото 9). Здесь впервые на Северо-Востоке был обнаружен многослойный памятник, содержащий палеолитические слои с четкой стратиграфией, строго контролируемой пепловыми прослойками. Раскопанная часть стоянки Ушки I составила к началу 1990-х гг. 5 тыс. м² (Диков, 1993а). Н. Н. Диковым исследовалась ранняя ушковская палеолитическая культура, где были выявлены 10 наземных жилищ и одиночное погребение. Комплекс этого слоя не имеет аналогов среди позднепалеолитических культур Сибири и Дальнего Востока. В поздней ушковской палеолитической культуре, представленной VI слоем, исследовано более 40 разных по типам жилищ с интересным каменным инвентарем. Открытие палеолитических стоянок стало большим событием в археологии Дальнего Востока. Многие годы начальником Ушковского отряда был Н. Н. Диков. Последний раз Н. Н. Диков работал на стоянке Ушки I в 1993 г. Чтобы увеличить объемы работ и раскопать большую площадь, в 1980-е гг. на Ушки завезли траспортеры. В планах Н. Н. Дикова предполагалось дальнейшее развитие археологических работ на многослойных палеолитических стоянках на Ушковском озере, где, по его мнению, необходимо было создать постоянную базу, а впоследствии, возможно, и стационар (Диков, 1985). Для осуществления разведочных работ в долине р. Камчатка в сентябре 1988 г. с Чукотки на территорию Ушковского рыбвода перевезли вездеход (ответственными за эту переброску назначались сотрудники ла- прошу разрешить увеличение группь археологов в лаборатории археологии, истории и этнографии ... В настоящее время в лаборатории имеется (не считая меня) три археолога: м. н. с. Дикова Т. М., м. н. с. Теин Т. С. и аспирант Лебединцеев А. И. Это крайне недостаточно для обеспечения археологических разведок и раскопок в масштабах, соответствуюших огромному международному научному и политическому значению археологической проблематики в нашем регионе (проблемь первоначального заселения СевероВостока Азии и Америки, происхождения и развития народов Северо-Востока и др.) ... В перспективе (в 1980-1981 г2.) крайне желательно расширение группы археологов ещзе на несколько сотрудников ...» (Архив лаборатории).

Заботой Н. Н. Дикова также было обеспечение финансированием полевых отрядов. Так, в 1976 г. из-за сокращения расходов на полевые работы выделенных средств хватило только на экспедиции аспирантов Т. С. Теина и А. А. Орехова. На 1977 г., например, планировалась организация 5 археологических и 3 этнографических отрядов (по информации из рапорта Н. Н. Дикова директору СВКНИИ ДВНЦ АН СССР академику Н. А. Шило от 22. 12. 1976 г.). Запланированные полевые исследования соответствоваее тематики, учитывая растущее значение общественных наук на Северо-Востоке СССР. Обеспокоен Н. Н. Диков был и крайне ограниченными издательскими возможностями, предоставляемыми ДВНЦ Северо-Восточному комплексному научно-исследовательскому институту.

В конце 1980-х гг. обсуждалась возможность создания общественно-гуманитарного академического института в Магадане, и Н. Н. ли росту и развитию лаборатории, актуальности 
Диков задумывался о создании нескольких археологических лабораторий (палеолита, неолита, железного века). Для этого необходимы были специалисты, часть которых предполагалось привлечь из других городов. Но наступили другие времена, и все надежды в одночасье рухнули ...

Николай Николаевич Диков как исследователь и организатор науки на Севере Дальнего Востока внес значительный вклад в изучение древних культур. Открытие Н. Н. Диковым палеолита на Камчатке, Колыме и Чукотке - главный результат его археологических исследований. Не менее значительных результатов добился Н. Н. Диков в изучении более поздних голоценовых культур Северо-Востока, многие из которых он открыл для науки впервые (мезолит, ранний неолит Камчатки, Колымы и Чукотки, палеоэскимосская культура на о. Врангеля). Им дана характеристика и обоснованная хронология древних культур Камчатки и Чукотки. Важные результаты были достигнуты Н. Н. Диковым в разработке концепции этнокультурной дифференциации археологических общностей Северо-Востока Азии (фото 10).

Значительные успехи были достигнуты Н. Н. Диковым в изучении эскимосской проблемы. Он высказал мнение, что предки эскимосов рас-

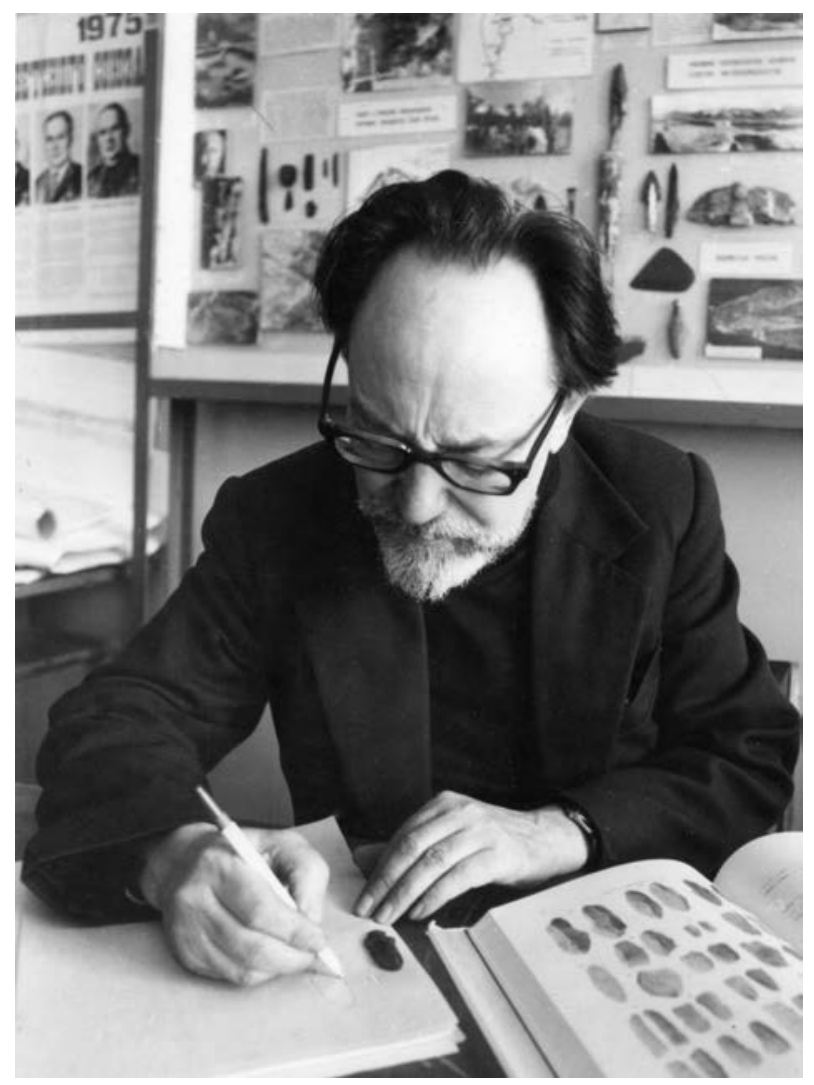

Фото 10. Н. Н. Диков зарисовывает находки Photo 10. N. N. Dikov sketching finds пространились по берингийской суше из Азии в Северо-Западную Америку еще в конце плейстоцена - начале голоцена, а затем уже на территории Южной, Юго-Западной Аляски и Западной Канады потомки тех переселенцев сформировались в эскимосскую этнокультурную общность. Н. Н. Диковым была выделена канчаланская культура и определены критерии ее выделения. Стоянки этой культуры принадлежали внутриконтинентальным охотникам, осевшим у моря и имевшим комплексное хозяйство, сочетающее охоту на оленей и морской зверобойный промысел. Появление этой культуры относится к концу І тыс. н. э., а просуществовала она, вероятно, до XVI в. Им рассмотрена проблема возникновения зверобойного промысла и предложена вполне обоснованная схема развития древних культур этого региона.

Благодаря созданию СВАКАЭ удалось открыть и исследовать множество археологических стоянок на Чукотке, Камчатке, Колыме и Охотском побережье, а также охватить изучением обширнейшие территории Севера Дальнего Востока.

Николай Николаевич Диков - ученый, обогативший мировую и отечественную науку трудами огромного значения, внесший важный вклад в становление и развитие академической науки на Дальнем Востоке.

\section{ЛИТЕРАТУРА}

Археологические исследования на Севере Дальнего Востока (по данным Северо-Восточно-Азиатской комплексной археологической экспедиции). Магадан : СВКНИИ ДВО РАН, 1996. 160 с.

Гоков А. В. К изучению материальной культуры русского населения Камчатки (по раскопкам города Нижне-Камчатска XVIII-XIX вв. на реке Радуге) // Краеведческие записки. Петропавловск-Камчатский : Дальневост. кн. изд-во, 1989. Вып. 6. С. 69-90.

Гоков A. B. Первые итоги раскопок города Нижнекамчатска XVIII-XIX вв. // Древние памятники севера Дальнего Востока (Новые материалы и исследования Северо-Восточно-Азиатской комплексной археологической экспедиции). Магадан : СВКНИИ ДВО АН CCCP, 1990. С. 142-155.

Диков Н. Н. Азия на стыке с Америкой в древности: Каменный век Чукотского полуострова. СанктПетербург : Наука, 1993a. 304 с.

Диков Н. Н. Археологические памятники Камчатки, Чукотки и Верхней Колымы : (Азия на стыке с Америкой в древности). Москва : Наука, 1977. 391 с.

Диков Н. Н. Древние костры Камчатки и Чукотки: 15 тысяч лет истории. Магадан : Кн. изд-во, 1969. $256 \mathrm{c.}$

Диков Н. Н. Древние культуры Северо-Восточной Азии: Азия на стыке с Америкой в древности. Москва : Наука, 1979. 352 с.

Диков Н. Н. Комплексная гуманитарная лаборатория // Колыма. 1985. № 3. С. 41-43. 
Диков Н. Н. Наскальные загадки древней Чукотки: Петроглифы Пегтымеля. Москва : Наука, 1971. 130 с.

Диков Н. Н. Новейшие исследования палеолита на Колыме и Камчатке и проблема первоначального заселения Американского континента // Экономические и исторические исследования на СевероВостоке СССР. Магадан, 1976. С. 165-182. (Тр. СВКНИИ ; вып. 67).

Диков Н. Н. Палеолит Камчатки и Чукотки в связи с проблемой первоначального заселения Америки. Магадан : СВКНИИ ДВО РАН, 1993б. 68 с.

Дикова T. М. Археология южной Камчатки в связи с проблемой расселения айнов. Москва : Наука, 1983. $232 \mathrm{c}$.

Древние памятники Севера Дальнего Востока (новые материалы и исследования Северо-Восточ-ноАзиатской комплексной археологической экспедиции). Магадан : СВКНИИ ДВО АН СССР, 1990. 181 с.

Иванов В. Ф. Проблемы геоморфологии и четвертичной геологии в районе стоянки Ушки (долина реки Камчатки) // Древние памятники Севера Дальнего Востока (новые материалы и исследования Северо-ВосточноАзиатской комплексной археологической экспедиции) Магадан : СВКНИИ ДВО АН СССР, 1990. С.161-170.

Кирьяк М. А. Археология Западной Чукотки в связи с юкагирской проблемой. Москва : Наука, 1993. $224 \mathrm{c}$.

Лебединцев А. И. Древние приморские культуры Северо-Западного Приохотья. Ленинград : Наука, $1990.260 \mathrm{c}$.

Новейшие данные по археологии Севера Дальнего Востока (материалы Северо-Восточно-Азиатской комплексной экспедиции). Магадан : СВКНИИ ДВНЦ AH CCCP, 1980. 159 c.

Новое в археологии Севера Дальнего Востока (материалы Северо-Восточно-Азиатской комплексной экспедиции). Магадан : СВКНИИ ДВНЦ АН СССР, 1985. $178 \mathrm{c}$.

Hoвые археологические памятники Севера Дальнего Востока (по данным Северо-Восточно-Азиатской комплексной археологической экспедиции). Магадан : СВКНИИ ДВНЦ АН СССР, 1979. 155 с.
Орехов А. А. Древняя культура Северо-Западного Берингоморья. Москва : Наука, 1987. 174 с.

Очерки истории Чукотки с древнейших времен до наших дней. Новосибирск : Наука, 1974. 156 с.

Пономаренко А. К. Древняя культура ительменов Восточной Камчатки. Москва : Наука, 1985. 216 с.

Пташинский A. В. Культура охотников на морского зверя северо-восточного побережья Охотского моря (I-II тыс. н. э.) : автореф. дис. ... канд. ист. наук. Москва, 2002. 23 с.

Пташинский A. B. Новые стоянки побережья Пенжинской губы // Краеведческие записки. Петропавловск-Камчатский : Дальневост. кн. изд-во, 1989. Вып. 6. С. 91-118.

Пташинский A. В. Предварительные результаты археологической разведки на полуострове Елистратова // Древние памятники Севера Дальнего Востока (новые материалы и исследования СевероВосточно-Азиатской комплексной археологической экспедиции). Магадан : СВКНИИ ДВО АН СССР, 1990. С. 87-99.

Рубан В. И. Предварительные результаты археологической разведки на западном побережье Камчатки // Новые археологические памятники Севера Дальнего Востока (по данным Северо-ВосточноАзиатской комплексной археологической экспедиции). Магадан : СВКНИИ ДВНЦ АН СССР, 1979. С. 107-128.

Слободин С. Б. Каменный век Верхней Колымы и Континентального Приохотья : автореф. дис. ... канд. ист. наук. Новосибирск, 1995. 18 с.

Теин T. С. Древнеэскимосская культура Северной Чукотки, включая остров Врангеля и Ратманова : автореф. дис. ... канд. ист. наук. Ленинград, 1991. 18 с.

Теин T. С. Тайна Чертова Оврага. Магадан : Кн. изд-во, 1983. 94 с.

Титов Э. Э. Геоморфология и условия накопления осадков в районе ушковских стоянок // Новейшие данные по археологии Севера Дальнего Востока (материалы Северо-Восточно-Азиатской комплексной экспедиции). Магадан : СВКНИИ ДВНЦ АН СССР, 1980. C. 134-156.

\title{
NIKOLAY N. DIKOV - ORGANIZER OF ARCHEOLOGICAL RESEARCH IN THE NORTH-EAST RUSSIA
}

\author{
A. I. Lebedintsev
}

\section{North-East Interdisciplinary Scientific Research Institute n. a. N. A. Shilo, FEB RAS, Magadan}

The article presents data on the scientific and organizational activities of the Head of the NEISRI Laboratory of Archeology, History, and Ethnography, Doctor of Historical Sciences, Professor, Corresponding Member of the Russian Academy of Sciences N. N. Dikov as well as on the creation of the North-East Asian Complex Achaeological Expedition (NEACAE) and the results of archaeological research performed by its detachments. N. N. Dikov's important contribution to the organization of archaeological research in the North-East Russia and his achievements in the study of ancient cultures are noted. The NEACAE formation contributed to a greater coverage of 
the territory of the north of the Far East by archaeological research, the discovery of a significant number of archaeological sites in Chukotka, Kamchatka, Kolyma, and on the Okhotsk coast.

\section{Keywords: archaeological research, North-East Asian Complex Archaeological Expedition, NEISRI, N. N. Dikov, North-East Russia.}

\section{REFERENCES}

Ancient Monuments of the North of the Far East (New Materials and Research of the North-East Asian Complex Archaeological Expedition), 1990. Magadan, SVKNII DVO AN USSR [In Russian].

Archaeological Studies in the North of the Far East (by the Data of the North-East Asian Complex Archaeological Expedition), 1996. Magadan, NEISRI FEB RAS [In Russian].

Dikov, N. N., 1969. Ancient Fires of Kamchatka and Chukotka (15 Thousand Years of History). Magadan, Book Publishing House [In Russian].

Dikov, N. N., 1971. Rocky Riddles of Ancient Chukotka : Petroglyphs of Pegtymel. Moscow, Nauka [In Russian]. Dikov, N. N., 1976. Recent Studies of the Paleolithic in Kolyma and Kamchatka and the Problem of the Initial Peopling of the American Continent, Economic and Historical Research in the North-East of the USSR, Trudy SVKNII DVNC AN USSR. 165-182 [In Russian].

Dikov, N. N., 1977. Archaeological Sites of Kamchatka, Chukotka, and Upper Kolyma : (Asia at the Junction with America in Antiquity). Moscow, Nauka [In Russian].

Dikov, N. N., 1979. Ancient Cultures of North-East Asia: Asia at the Junction with America in Antiquity. Moscow, Nauka [In Russian].

Dikov, N. N., 1985. Complex Humanitarian Laboratory, Kolyma. 3, 41-43 [In Russian].

Dikov, N. N., 1993a. Asia at the Junction with America in Antiquity : The Stone Age of the Chukchi Peninsula. St. Petersburg, Nauka [In Russian].

Dikov, N. N., 1993b. Paleolithic of Kamchatka and Chukotka in Connection with the Problem of the Initial Settlement of America. Magadan, NEISRI FEB RAS [In Russian].

Dikova, T. M., 1983. Archeology of Southern Kamchatka in Connection with the Ainu Settlement Problem. Moscow, Nauka [In Russian].

Essays on the History of Chukotka from the Ancient Times to the Present Day, 1974. Novosibirsk, Nauka [In Russian].

Gokov, A. V., 1989. To the Study of the Material Culture of the Russian Population of Kamchatka (by the Excavations of the City of Nizhne-Kamchatsk on the Raduga River in the $18^{\text {th }}-19^{\text {th }}$ Centuries ), Kraevedcheskiye Zapiski. Petropavlovsk-Kamchatsky. Iss. 6, 69-90 [In Russian].

Gokov, A. V., 1990. First Results of the Excavations of the City of Nizhnekamchatsk in the $18^{\text {th }}-19^{\text {th }}$ Centuries, Ancient Monuments of the North of the Far East (New Materials and Research of the North-East Asian Complex Archaeological Expedition). Magadan, SVKNII DVO AN USSR. 142-155 [In Russian].

Ivanov, V. F., 1990. Problems of Geomorphology and Quaternary Geology in the Area of the Ushki Site (Valley of the Kamchatka River), Ancient Monuments of the North of the Far East (New Materials and Research of the NorthEast Asian Complex Archaeological Expedition). Magadan, SVKNII DVO AN USSR. 161-170 [In Russian].
Kiryak, M. A., 1993. Archeology of Western Chukotka in Connection with the Yukagir Problem. Moscow, Nauka [In Russian].

Latest Archaeological Monuments in the North of the Far East (by the Data of the North-East Asian Complex Archaeological Expedition), 1979. Magadan [In Russian].

Lebedintsev, A. I., 1990. Ancient Maritime Cultures of the North-Western Priokhotye. Leningrad, Nauka [In Russian].

New Archaeological Monuments in the North of the Far East (According to the Data of the North-East Asian Complex Archaeological Expedition), 1979. Magadan [In Russian].

Orekhov, A. A., 1987. Ancient Culture of the Northwest of the Bering Sea Area. Moscow, Nauka [In Russian].

Ponomarenko, A. K., 1985. Ancient Itelmen Culture of Eastern Kamchatka. Moscow, Nauka [In Russian].

Ptashinsky, A. V., 1989. New Sites on the Coast of the Penzhina Bay, Kraevedcheskiye Zapiski. PetropavlovskKamchatsky. Iss. 6, 91-118 [In Russian].

Ptashinsky, A. V., 1990. Preliminary Results of Archaeological Exploration on the Elistratov Peninsula, Ancient Monuments of the North of the Far East (New Materials and Research of the North-East Asian Complex Archaeological Expedition). Magadan, SVKNII DVO AN USSR. 87-99 [In Russian].

Ptashinsky, A. V., 2002. Culture of Sea Animal Hunters on the Northeast Coast of the Sea of Okhotsk (I-II Millennium AD) : Avtoref. Dis. ... Cand. Ist. Nauk. Moscow [In Russian].

Ruban, V. I., 1979. Preliminary Results of Archaeological Exploration on the West Coast of Kamchatka, New Archaeological Sites of the North of the Far East (by the Data of the North-East Asian Complex Archaeological Expedition). Magadan, SVKNII DVNC AN USSR. 107128 [In Russian].

Slobodin, S. B., 1995. Stone Age of the Upper Kolyma and Continental Priokhotye : Avtoref. Dis. ... Cand. Ist. Nauk. Novosibirsk [In Russian].

Tein, T. S., 1983. Mystery of the Devil's Ravine, Magadan [In Russian].

Tein, T. S., 1991. Ancient Eskimo Culture of Northern Chukotka, Including Wrangel and Ratmanov Islands : Avtoref. Dis. ... Cand. Ist. Nauk. Leningrad [In Russian].

The Latest Data on the Archeology in the North of the Far East (Materials of the North-East Asian Complex Archaeological Expedition), 1980. Magadan, SVKNII DVNC AN USSR [In Russian].

The New in the Archeology of the North of the Far East (Materials of the North-East Asian Complex Archaeological Expedition), 1985. Magadan [In Russian].

Titov, E. E., 1980. Geomorphology and Conditions of Sediment Accumulation in the Area of the Ushki Sites, The Latest Data on the Archeology of the North of the Far East (Materials of the North-East Asian Complex Expedition). Magadan, SVKNII DVNC AN USSR. 134 156 [In Russian]. 